\title{
¿A dónde vamos? Condiciones socioeconómicas y las modalidades frecuentadas por los hogares colombianos para la compra de alimentos ${ }^{1}$
}

\author{
Where do we go? Households socioeconomic conditions and \\ grocery in Colombia \\ Giselle Torres-Pabon ${ }^{1}$ (1) \\ 'Facultad de Ciencias Económicas y Empresariales, Universidad Santiago de Cali, Cali, Colombia. E-mail: gtorres1@uc.cl
}

\begin{abstract}
Como citá: Torres-Pabón, G. (2022). ¿A dónde vamos? Condiciones socioeconómicas y las modalidades frecuentadas por los hogares colombianos para la compra de alimentos. Revista de Economia e Sociologia Rural, 60(spe), e230404. https://doi.org/10.1590/1806-9479.2021.230404
\end{abstract}

\begin{abstract}
Resumen: El objetivo de este artículo es analizar la relación entre condiciones socioeconómicas de los hogares colombianos y los lugares que estos frecuentan para la obtención de alimentos, durante el periodo 1993-2014. La pregunta para responder es: ¿cómo las condiciones socioeconómicas de los hogares se asocian con los usos de una modalidad de abastecimiento de alimentos en Colombia en dicho periodo? Se utiliza la Encuesta Nacional de Calidad de Vida, realizada por el Departamento Nacional de Estadística colombiano para los años 1993, 1997, 2010 y 2014. La metodología que se sigue es cuantitativa. Los resultados se dividen en dos partes. La primera presenta un análisis descriptivo; y la segunda expone los resultados de la estimación de un modelo multinomial, donde la variable dependiente son las modalidades que utilizan los hogares para el abastecimiento de alimentos (1. Comercial, 2. No comercial y 3. Ambas modalidades). Las variables independientes corresponden a las características socioeconómicas de los hogares: cantidad de mujeres, cantidad de personas, nivel educativo, sector (Urbano/Rural). Los resultados demuestran un incremento en el uso de las modalidades comerciales en el periodo de análisis y revelan vulnerabilidad alimentaria para diferentes grupos de la sociedad colombiana, especialmente para la mujer colombiana.
\end{abstract}

Palabras clave: práctica alimentaria, hogares, condiciones socioeconómicas, lugares de abastecimiento, alimentos, cambio, vulnerabilidad alimentaria, Colombia.

\begin{abstract}
This article aims to analyze the relationship between Colombian households' socioeconomic conditions and the places they frequent for obtaining food during the period 1993-2014. The question to be answered is: how do the socioeconomic conditions of households affect the chances (odds) of choosing a type of food supply place in Colombia in that period? I used the National Survey of Quality of Life (ENCV), conducted by the Colombian National Department of Statistics for 1993, 1997, 2010, and 2014. The methodology followed is quantitative. The results are divided into two parts. The first presents a descriptive analysis. The second one exposes an inferential statistical analysis, a multinomial regression, in which the dependent variable is the modalities that households use for the food supply (1. Commercial, 2. Non-commercial, and 3. Both). The independent variables correspond to the households' socioeconomic characteristics: number of women, number of people, educational level, sector (Urban / Rural). I can say that Colombian households are using more commercial modalities, and women are vulnerable to food access.
\end{abstract}

Keywords: food practice, households, socioeconomic conditions, grocery, food, change, food security, Colombia.

\footnotetext{
Esta investigación fue posible gracias a la Comisión Nacional de Investigación Científica y Tecnológica de Chile, CONICYTPCHA/Beca Doctorado Nacional/2017-21170258, y al Instituto de Sociología de la Pontificia Universidad Católica de Chile. También quiero agradecer a la Dirección General de Investigaciones de la Universidad Santiago de Cali quienes bajo la convocatoria No. 01-2021 patrocinaron la edición y publicación de este artículo.
} 


\section{Introducción}

La Constitución Política colombiana de 1991 reestructuró diversos elementos políticos, económicos y sociales, que afectaron la vida cotidiana en el país. Por eso, Colombia aún transita entre lo tradicional y lo moderno, entre lo rural y lo urbano, entre el fortalecimiento del campo y la apertura económica (Perry, 2011). Un aspecto que refleja dichas paradojas es la práctica alimentaria. En Colombia, la práctica alimentaria se está redefiniendo por las nuevas demandas y ofertas comerciales, y los nuevos discursos e imaginarios alimentarios. Una variable analítica como los lugares de abastecimiento ayuda a conocer y comprender dichas transformaciones. El sistema agroalimentario y las formas de producción, comercialización y consumo de alimentos en un país como Colombia toman diferentes caminos en comparación con los países europeos o industrializados, como Estados Unidos o Australia, en términos de: 1. tipos de lugares (almacenes de cadena, tiendas de barrio, cajas de compensación, plazas de mercados, mercados móviles y/o galerías); 2 . acuerdos de comercialización: pago en especie, intercambio y/o trueque; 3. productos alimentarios; entre otros.

De manera paralela, durante el periodo analizado, Colombia vivió un largo e intenso conflicto armado, entre diferentes guerrillas, grupos paramilitares y fuerzas militares del Estado, lo que ocasionó prolongados periodos de violencia, desplazamientos forzados y despojo de tierras. De modo que no se debe perder de vista que las posibilidades y las distintas formas de abastecimiento de alimentos en los hogares (autoproducción, regalo, trueque y mercados) son categorías analíticas que conectan diferentes elementos de los hogares y de las condiciones socioeconómicas del país. A partir de lo anterior, la pregunta teórica general que guía este artículo es: ¿Cómo las condiciones socioeconómicas se asocian con los usos de los lugares de abastecimiento de alimentos de los hogares, en el tiempo y en el espacio? Y en términos empíricos: ¿Cómo las condiciones socioeconómicas de los hogares colombianos se asocian con los usos de las modalidades de abastecimiento de alimentos entre 1993 y 2014 ? Pero más aún, bajo el contexto de las profundas transformaciones que ha experimentado Colombia en su estructura productiva, este artículo busca saber ¿cuáles han sido las transformaciones en los usos de los lugares y las modalidades de abastecimiento de alimentos en los hogares colombianos durante el periodo analizado?

En dicho orden de ideas, el objetivo de este artículo es analizar la relación entre condiciones socioeconómicas de los hogares colombianos y los lugares que estos frecuentan para la obtención de alimentos, durante el periodo 1993-2014. La metodología que se sigue es cuantitativa. Los resultados se dividen en dos partes. La primera presenta un análisis descriptivo; y la segunda expone un análisis inferencial, a partir de una regresión multinomial, donde la variable dependiente son las modalidades que utilizan los hogares para el abastecimiento de alimentos (1. Comercial, 2. No comercial y 3. Ambas modalidades). Las variables independientes corresponden a las características socioeconómicas de los hogares: cantidad de mujeres, cantidad de personas, nivel educativo, sector (Urbano/Rural).

\section{Marco Analítico}

La práctica alimentaria en los hogares se compone de diferentes etapas o procesos: aprovisionamiento, preparación, ingesta, desechos, entre otros (Holm \& Kjærnes, 2006; Poulain, 2002; Régnier et al., 2006; Warde, 1997, 2016). Bajo la perspectiva de la Sociología del Consumo de Alimentos y la Sociología del Mercado, es posible decir que cada una de estas etapas -como prácticas del hogar - se desarrolla bajo determinadas condiciones de posibilidad o de limitación, ya sea del agente o de la estructura en la que la práctica alimentaria toma existencia. En otras 
palabras, la práctica alimentaria se configura a partir de la interconexión de múltiples etapas o procesos; se desarrolla bajo un conjunto de condiciones socioeconómicas materiales y nomateriales, tanto del agente como de la estructura; y estas condiciones pertenecen a diversos niveles de la realidad, ya sean estos niveles micro o macro; correspondientes a un espacio y tiempo determinado (Figura 1).

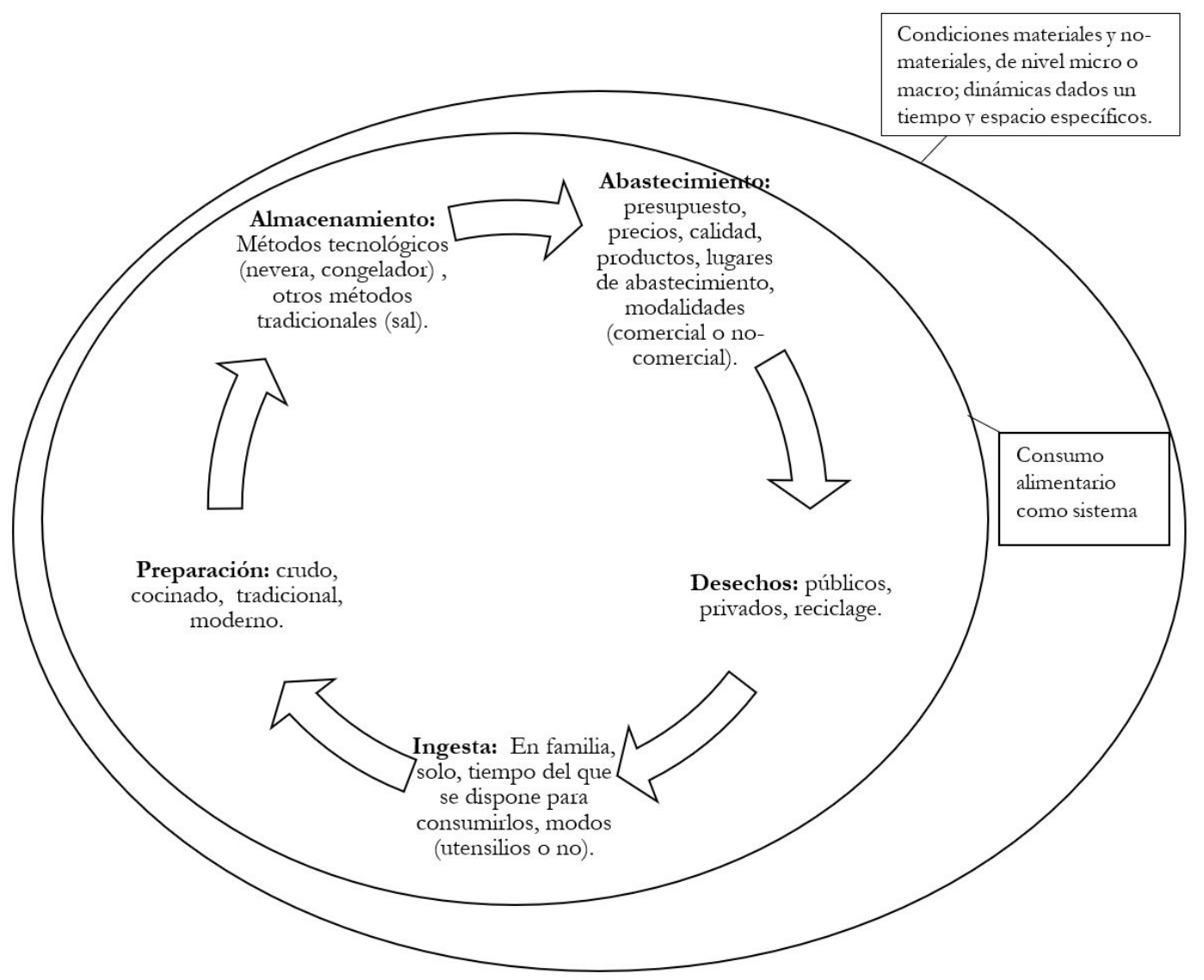

Figura 1. Modelo teórico sistémico y socioeconómico para la comprensión del uso de las modalidades de abastecimiento de alimentos. Fuente: Elaboración propia.

Si bien debe ser claro para el lector que la práctica alimentaria se compone de diferentes etapas, y estas etapas se hacen posibles (o no) por diferentes condiciones de posibilidad (o limitación), este texto se enfoca - de la práctica alimentaria- en el aprovisionamiento de alimentos en los hogares; $y$-del aprovisionamiento- a los lugares y/o modalidades de abastecimiento que los hogares frecuentan para abastecerse en el consumo de alimentos.

En línea con la Sociología Económica, la Sociología del Mercado y la Sociología de la Alimentación, puede decirse que, tanto en las modalidades comerciales como en las no-comerciales, se construyen vínculos a partir de la interacción social del intercambio. Estos vínculos pueden ser familia-familia, amigo-amigo, amigo-familia, tribu-amigo, vendedor-cliente (Le Velly, 2012). Sin embargo, los usos de determinadas modalidades para el abastecimiento (comercial, no-comercial, o ambas) y la elección de determinados lugares y formas de intercambio no dependen sólo de quienes participan en los intercambios. Son necesarios un conjunto de dispositivos materiales que hacen posible el uso de dicha modalidad, lugar y/o forma de intercambio (DubuissonQuellier, 1999; Gojard \& Véron, 2018; Larmet, 2002). 
De modo que puede decirse que en la práctica² alimentaria, y en concreto en el aprovisionamiento, los hogares conjugan sus saberes, sus motivaciones y sus condiciones materiales para abastecerse. Y, dentro del aprovisionamiento, el uso de las modalidades de abastecimiento de alimentos (comerciales, no-comerciales o ambas) pone de manifiesto lo subyacente en la práctica (actividades, know-how(s) ${ }^{\beta}$, usos, formas de comprender al mundo, habilidades, motivaciones o elementos materiales). Por lo tanto, en la práctica alimentaria y en el aprovisionamiento en los hogares, en términos teóricos, se supone la existencia de un gran conjunto de elementos socioeconómicos, materiales y no materiales, de diferentes niveles, que la hacen posible (o no). Pero más aún, estas posibilidades (o limitaciones) para ejercer la práctica responden a modos de vida estratificados (bajo, medio, alto; rural o urbano).

En este orden de ideas, las modalidades (comercial, no comercial o ambas), los lugares (mercados, supermercados, grandes superficies) y las formas (compra, regalo, intercambio) que los hogares escogen para abastecerse de alimentos hacen explícitas las condiciones socioeconómicas estructurales y agenciales en las que los hogares ejecutan la práctica alimentaria, en especial el aprovisionamiento (Eymard, 1999; Gojard \& Véron, 2018; Larmet, 2002; Lhuissier, 2006). Por ejemplo, los hogares pertenecientes a las zonas rurales tienen una propensión mayor al uso de modalidades de autoproducción, mientras que los hogares de las zonas urbanas tienden a las modalidades comerciales como supermercados, grandes superficies y/o tiendas especializadas. O, en otro caso, los niveles de ingreso y de educación o la ocupación profesional pueden determinar el uso de determinada modalidad o lugar de abastecimiento de los alimentos comercial-especializado, comercial-popular (Bonnain-Moerdijk, 1975; Gojard \& Véron, 2018; Larmet, 2002; Lhuissier, 2018).

Así pues, lo que en este artículo se propone es pensar en los usos de los lugares o de las modalidades de abastecimiento como una práctica en la que los hogares utilizan sus ventajas (o desventajas) en habilidades, saberes, posibilidades materiales y/o motivaciones (Reckwitz, 2002; Schatzki et al., 2001). Es decir, los hogares hacen uso de sus conocimientos, saber-hacer, motivaciones, estados de ánimo, preferencias; sobre los productos alimentarios que consumen y los lugares que deben frecuentar para abastecerse, en términos de precios, calidades, ofertas (días, semanas, meses), temporadas (fiestas, verano, invierno), lugares (ferias, mercados, supermercados, grandes superficies). Además, se debe decir que dicho uso es posible por las posibilidades (o limitaciones) materiales y no-materiales que la hacen posible (o no-posible). De modo que estamos hablando de un gran conjunto de dispositivos, mecanismos y condiciones materiales y no materiales; de diferentes niveles (micro o macro); en diferentes esferas de la vida cotidiana (social, política, económica); en lugares y tiempos específicos (Dubuisson-Quellier, 1999; Gojard \& Véron, 2018; Le Velly, 2012; Steiner, 2011).

El estudio de los mercados desde una perspectiva socioeconómica ha tomado lugar mayoritariamente en la Sociología económica y/o en la Sociología del mercado (Le Velly, 2012; Mauss, 1971; Steiner, 2011). Y en lo que respecta a los lugares de abastecimiento de alimentos debe decirse que estos han sido poco estudiados en la Sociología del Consumo de Alimentos (Gojard \& Véron, 2018; Larmet, 2002; Lhuissier, 2006). De los artículos que se han dedicado a analizar el abastecimiento de alimentos en los hogares, Larmet (2002), a partir del estudio de las encuestas del Institut national de la statistique et des études économiques ${ }^{4}$, plantea que la organización de las compras de alimentos depende tanto de los consumidores (tiempo e

2 Entendida como un tipo de comportamiento rutinario que interconecta formas de ver el mundo, costumbres, motivaciones, elementos materiales, saberes, ventajas, desventajas, saberes, entre otros (Reckwitz, 2002; 249, 250).

3 Saber hacer.

${ }^{4}$ Instituto Nacional de Estadística y de Estudios Económicos. 
ingresos disponibles) como de la oferta comercial (lugares, productos). Pero también, desde la perspectiva sociológica, el autor plantea que las compras de alimentos de los hogares están marcadas por diferencias de género y status. Por su parte, Lhuissier (2006), a partir de entrevistas en el norte de Francia, encuentra evidencia de que los hogares utilizan variados lugares para el aprovisionamiento alimentario, aunque dichos usos están constreñidos o limitados por las condiciones sociales y económicas de ellos. Finalmente, Gojard \& Véron (2018), en línea con la teoría de la práctica y un estudio etnográfico, hallaron que los hogares - de acuerdo con sus características sociales- adoptan patrones para abastecerse, que dependen no sólo de las condiciones materiales (lugares, oferta), sino que también dicho aprovisionamiento está limitado por la organización temporal de los hogares para dicha actividad, así como el tamaño del hogar, sus ingresos y su posición social.

Teniendo como punto de partida dichos referentes, este texto parte de concebir al aprovisionamiento como una práctica de los hogares que se delimita por el contexto en el que la práctica toma existencia (lugares de abastecimiento, productos, precios, sectores: rural/ urbano, comercial/no-comercial); pero, al mismo tiempo, dicha práctica es posible (o no) dadas las características sociales y económicas de los hogares (presencia de mujeres en el hogar, niveles educativos, condiciones de vida, entre otros).

Este artículo se posiciona principalmente en la línea de Gojard \& Véron (2018) y busca ser un aporte al estudio de los lugares de abastecimiento de alimentos. Aunque son pocos los estudios que se enfocan en el análisis de la relación entre condiciones socioeconómicas y modalidades de abastecimiento de alimentos en los hogares, es innegable que el acceso a los alimentos es una necesidad vital de los hogares. A veces el acceso a los alimentos, para algunas personas, es un acto absolutamente naturalizado. Pero es verdad que, en contextos de alta pobreza y conflictos políticos o económicos, el acceso a los alimentos no es algo tan evidente o simple. Por lo que este artículo busca aportar, a partir de las condiciones socioeconómicas, bajo metodología cuantitativa, un panorama de las transformaciones de las modalidades de acceso a los alimentos de los hogares colombianos y su estratificación o diferenciación social. En Colombia este trabajo no había sido realizado bajo una perspectiva teórica socioeconómica, ni bajo esta metodología, ni en esta temporalidad; por lo que se espera que este trabajo sea una contribución en los estudios que se enfocan a comprender las prácticas alimentarias de los hogares $y$, especialmente, al estudio de las modalidades y lugares de abastecimiento de alimentos. Igualmente también es una invitación a seguir revisando lo que ocurre con el aprovisionamiento en otros lugares de América Latina, para identificar problemas y/o soluciones alrededor del acceso a los alimentos.

En Colombia, el aprovisionamiento de alimentos en los hogares puede ser bajo modalidades no comerciales, bajo modalidades comerciales o bajo el uso de ambas modalidades (comerciales y no comerciales). Para este texto, la modalidad comercial toma como punto de partida el intercambio del papel-moneda por el bien alimenticio. Así pues, si no hay un intercambio papel-moneda por alimentos, se considera que no es una modalidad de abastecimiento comercial. Dentro de las modalidades no comerciales se encuentran la autoproducción, el regalo o el trueque. Mientras que entre las modalidades comerciales se pueden citar lugares de abastecimiento en los que subyacen diferentes instrumentos para el intercambio, tales como el papel-moneda. Estos lugares de abastecimiento pueden ser: grandes superficies, hipermercados o almacenes de cadena, supermercados de barrio, pequeños mercados, graneros (almacenes no de cadena), tiendas, plazas de mercado, galerías o ferias.

De las modalidades no comerciales, en las que no hay un intercambio papel-moneda por el bien alimenticio, debe decirse que la autoproducción y el regalo son modalidades de abastecimiento 
sociales y económicas especiales. Primero, porque en la autoproducción, si bien no hay un intercambio papel-moneda por un bien alimenticio, son diversos los costos materiales y no materiales asociados a dicha actividad: saber-hacer ${ }^{5}$, el tiempo que es invertido en la siembra y cultivo, la inversión en maquinarias y otros recursos necesarios para el sostenimiento de la autoproducción. Y segundo, el regalo -como categoría teórica analítica-concibe un gran conjunto de incentivos de interacción social y cohesión (Mauss, 1971; Dufy \& Weber, 2007), que supone una inversión motivacional, emocional o de otro orden que da sentido a la acción del regalo (Mauss, 1971).

Todas estas modalidades, en sus respectivos contextos en el país, toman mayor (o menor) relevancia dependiendo de las regiones (Figura 2.), las zonas (urbano/rural), o las necesidades, limitaciones o posibilidades de los hogares colombianos. Especialmente, respecto a las regiones, debe tenerse presente que son altamente disímiles. La Figura 2 ilustra la ubicación de Colombia, de su capital y la configuración de las regiones.

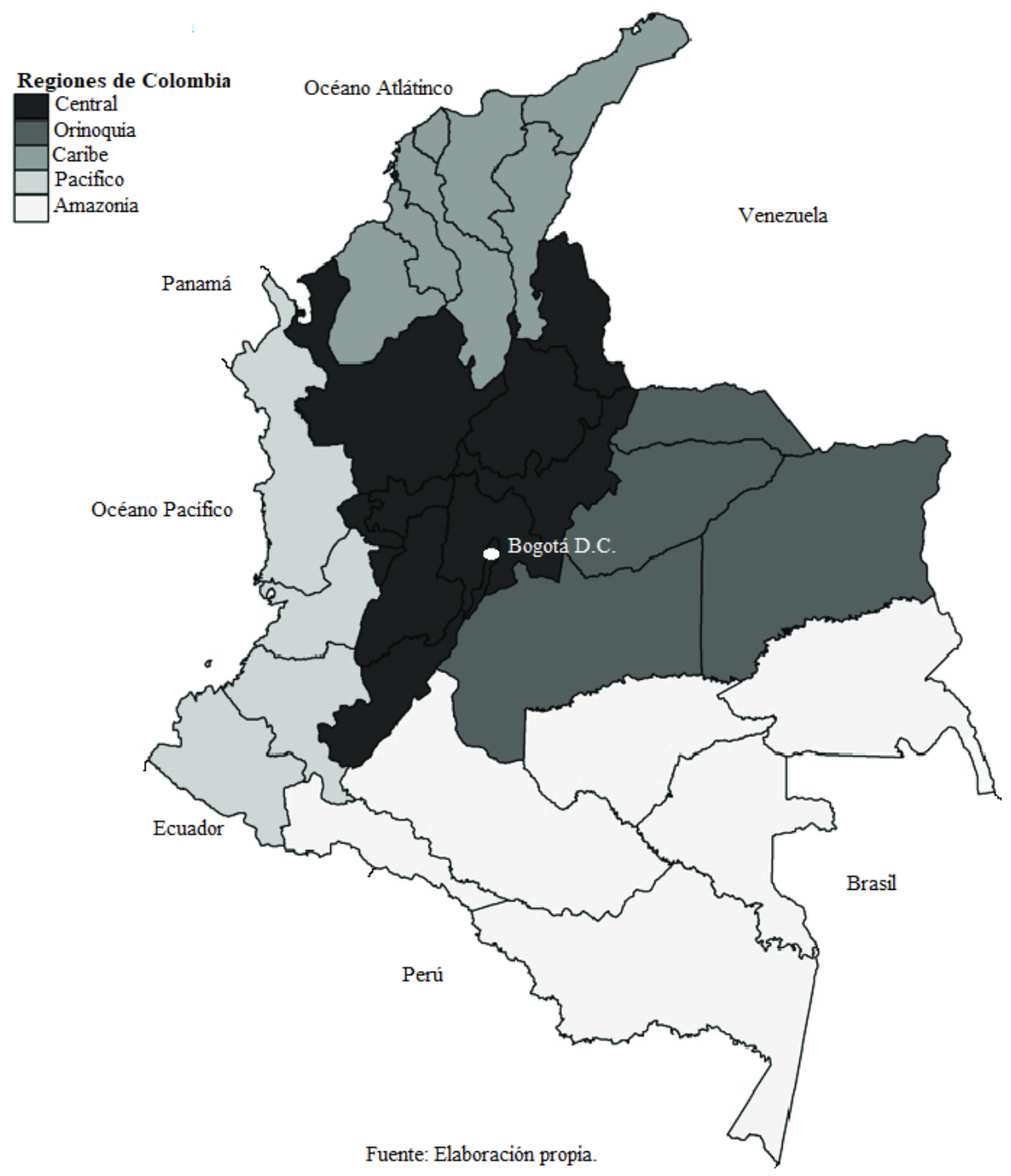

Figura 2. Mapa de Colombia.

${ }^{5}$ Sembrar, cuidar la siembra, manejar las plagas, cultivar. 
Por todo lo anterior, el lector debe saber que las modalidades y los lugares que los hogares eligen para abastecerse de alimentos -más allá del intercambio específico del papel-moneda por el bien alimenticio- son prácticas complejas y llenas de finos detalles. Son diferentes los costos, fijos y variables, materiales y no materiales, que son asumidos por los hogares para desarrollar cada modalidad. Y dependen de múltiples factores socioeconómicos, agenciales y estructurales, ya sean de nivel micro o macro, en el tiempo y en el espacio. Las hipótesis que guían esta investigación son:

1. El uso de las modalidades comerciales se incrementó en el periodo 1993-2014, bajo el supuesto de las transformaciones del sistema de oferta de alimentos en Colombia.

2. El uso de las modalidades comerciales se incrementa en las zonas urbanas, respecto a las zonas rurales; en hogares con hombres, respecto a la presencia de una mujer en el hogar; con altos niveles educativos, respecto a niveles educativos más bajos; y con altos niveles de condiciones de vida, respecto a condiciones de vida más bajas. Y esto también se espera en el tiempo. El test de Chow será utilizado para comparar el cambio en el tiempo.

Se espera que las modalidades comerciales (grandes superficies, supermercados, mercados y lugares especializados) tengan más chances en zonas urbanas porque son las zonas donde más se encontrarían este tipo de servicios, lo que facilitaría la disposición de su uso en dicha zona. Con mayores condiciones materiales de vida porque son quienes podrían acceder por recursos a estos bienes y servicios. En hogares compuestos de hombres porque son quienes más cuentan con ingresos propios para hacer transacciones monetarias y comerciales. Con una relación positiva con el grupo en edad de trabajar porque son quienes más dinamismo de consumo tienen.

Por lo tanto, en sentido contrario, se espera que las modalidades no comerciales (autoproducción, regalos, intercambios o trueques) tengan más chances en zonas rurales, en hogares con menores condiciones materiales, menores niveles educativos, con una relación positiva de la presencia de las mujeres en el hogar, con una relación negativa de la edad (retirados), todo en contraposición a lo explicado anteriormente,

\section{Datos y metodología}

A partir de la base teórica y empírica presentada en la sección anterior, se puede decir que este artículo tiene dirigida su atención al aprovisionamiento. Específicamente hacia los lugares de abastecimiento para alimentos, que pueden ser de modalidad comercial o no-comercial (Figura 3).

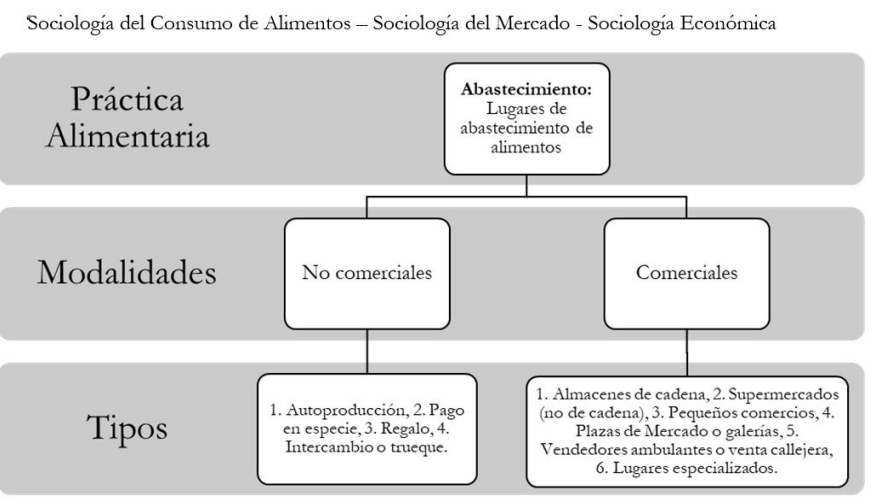

Figura 3. Esquema de análisis teórico y empírico. Fuente: Elaboración propia. 
En este artículo se utiliza la Encuesta Nacional de Calidad de Vida (ENCV) elaborada por el Departamento Nacional de Estadística de Colombia (DANE) y que corresponde a los años 1993, 1997, 2010 y 2014. La elección de años busca identificar patrones del gasto en alimentos (Gojard \& Véron, 2018; Halbwachs, 1933; Lhuissier, 2018). Dado que la ENCV no tiene una periodicidad constante, se escogieron la primera y la última ENCV que contienen la información de los lugares donde los hogares se abastecen de alimentos. Y se seleccionaron las encuestas que permitían obtener un patrón de distancia de cuatro años. Con estos puntos en el tiempo (1993, 1997, 2010 y 2014) se buscó encontrar un patrón de gasto en alimentos en Colombia6 . En otras palabras, la selección de los años de las encuestas fue una decisión metodológica pragmática (Heeringa et al., 2010). Esta encuesta es de cobertura nacional y tiene como propósito obtener información sobre las condiciones de vida de los hogares, sus ingresos y gastos totales. Como se señala en los documentos metodológicos de dicha encuesta, los resultados de la muestra son representativos de la población total; por tanto, los resultados se han expandido con el fin de producir estimaciones válidas.

De acuerdo con los documentos de la Encuesta Nacional de Calidad de Vida el hogar está definido como una persona o conjunto de personas que se asocian para compartir el alojamiento y la alimentación. Vale resaltar que la mayoría de los análisis es para 1997, 2010 y 2014 y se presenta información descriptiva que incluye el año 1993 porque para el año 1993 las preguntas de la encuesta son diferentes a las encuestas de los años posteriores. Los datos trabajados son los más nuevos disponibles.

Se desarrolló un modelo multinomial, en el que la variable dependiente es de respuesta múltiple (Comercial, No comercial o Ambas modalidades) e incluyen las siguientes categorías: 1. Comerciales (Categoría de referencia7): Almacenes de cadena o hipermercados, Supermercados o tiendas de barrio (no de cadena), Cajas de compensación, Comisariatos o cooperativas, Plaza de mercado o galería, Graneros o depósitos, Mercados móviles, Otros.

2. No comerciales: Finca, Pago en especie, Regalo, Intercambio o trueque.

3. Ambas modalidades: comerciales o no comerciales.

Ahora bien, aunque no son muchos los artículos que se han enfocado en el análisis de los lugares de abastecimiento de alimentos bajo esta metodología, las variables independientes a estimar vienen de la literatura que se enfoca en el análisis del consumo de alimentos en los hogares (Poulain, 2002; Régnier et al., 2006; Warde, 1997) y todas en conjunto buscan modelar las condiciones socioeconómicas de los hogares colombianos: 1. Al menos una mujer en el hogar, que busca conocer la asociación de su presencia en el hogar. Dado que se ha encontrado que son quienes lideran las acciones del cuidado del hogar y sus integrantes, especialmente lo que constituye el cuidado y administración de los alimentos (Gojard et al., 2017). 2. Edad del Jefe del hogar, lo que implica el ciclo de vida en la práctica alimentaria (Bove \& Sobal, 2006; Plessz et al., 2014). Mientras que: 3. Nivel educativo máximo del hogar (Menor, Superior o más) y 4. Condiciones materiales del hogar - Material del piso (a. Tierra, b. Cemento, c. Madera, d. Cerámica, Mármol) tienen por objetivo revisar las asociaciones de las condiciones materiales de los hogares con el abastecimiento de alimentos (Bourdieu, 1998; Grignon \& Grignon, 1980). Finalmente, las variables: 5. Cantidad de personas en el hogar, 6. Sector (Urbano/Rural) y 7.

\footnotetext{
${ }^{6}$ No se incluyó la ENCV para el año 2018, porque dicha encuesta ya no contiene estas preguntas. También vale la pena resaltar que no se desconoce el incrfoot emento de aplicaciones electrónicas para la compra y venta de alimentos en el país. Como tampoco ha sido pasado por alto el incremento de diferentes lugares de abastecimiento en diferentes ciudades de Colombia, pero con los datos disponibles (que no incluyen todas esas transformaciones) se busca presentar el panorama del abastecimiento de alimentos en Colombia.

7 Se escoge la categoría de referencia "Comercial” porque es la categoría en la que se da un intercambio papel-moneda por el bien alimenticio.
} 
Región (Central, Pacífico, Atlántico, Orinoquía, Amazonía, Bogotá D.C.) tienen por objetivo controlar las condiciones contextuales de la práctica alimentaria.

\section{Resultados}

Los resultados se dividen en dos secciones. La primera sección contiene estadística descriptiva, cuyo objetivo es exponer el panorama general de los usos de las diferentes modalidades y formas de abastecerse de alimentos de los hogares colombianos. Y la segunda parte presenta los resultados de la estimación del modelo multinomial, cuyo objetivo es probar las asociaciones estadísticamente significativas de las diferentes características socioeconómicas de los hogares colombianos.

\section{Análisis descriptivo}

En Colombia, entre 1993 y 2014, se encontró que los hogares utilizan diferentes modalidades para abastecerse: Comerciales, No comerciales o la combinación del uso de ambas modalidades. Como se presentó en el apartado de la metodología, cada modalidad contiene diferentes formas o lugares ${ }^{8}$. Pero el uso de cada modalidad, forma o lugar ha cambiado en el tiempo de análisis: la modalidad 'No comercial' disminuyó, al igual que el uso de ambas modalidades; mientras que el uso de la modalidad 'comercial' se incrementó de manera acelerada en el periodo analizado (Tabla 1).

Tabla 1. Modalidades usadas por los hogares, 1993-2014 (porcentaje).

\begin{tabular}{lcccc}
\multicolumn{1}{c}{ Modalidades } & $\mathbf{1 9 9 3}^{*}$ & $\mathbf{1 9 9 7}$ & $\mathbf{2 0 1 0}$ & $\mathbf{2 0 1 4}$ \\
Comercial y No comercial (Ambos) & 84.5 & 32.5 & 12.2 & 9.7 \\
No Comercial & 9.2 & 21.5 & 14.5 & 12.2 \\
Comercial & 6.3 & 46.0 & 73.3 & 78.1 \\
Total & $\mathbf{1 0 0}$ & $\mathbf{1 0 0}$ & $\mathbf{1 0 0}$ & $\mathbf{1 0 0}$ \\
\hline
\end{tabular}

*Nota: Para el año 1993 la pregunta fue ¿Consume de su propiedad? Fuente: Cálculos propios a partir de la ENCV 1993, 1997,2010 y 2014

Ahora bien, respecto a lo que corresponde con la modalidad 'No comercial', se puede afirmar que los hogares combinan los diferentes modos posibles de abastecerse. Y aunque ha disminuido aceleradamente el aprovisionamiento no comercial en los hogares, la autoproducción en finca y el regalo siguen siendo las categorías más utilizadas (Tabla 2).

Tabla 2. ${ }^{9}$ Modalidades de abastecimiento no comercial, 1997-2014 (N expandido - Porcentaje).

\begin{tabular}{|c|c|c|c|c|c|}
\hline 1000 & \multicolumn{5}{|c|}{ Finca } \\
\hline 100 & \multicolumn{5}{|c|}{ Pago en especie } \\
\hline 10 & \multicolumn{5}{|c|}{ Regalo } \\
\hline 1 & \multicolumn{5}{|c|}{ Intercambio o trueque } \\
\hline 0 & \multicolumn{5}{|c|}{ Ninguno } \\
\hline & 1997 & \multicolumn{2}{|c|}{2010} & \multicolumn{2}{|c|}{2014} \\
\hline 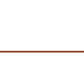 & Tipología Porcentaje & Tipología & Porcentaje & Tipología & Porcentaje \\
\hline
\end{tabular}

Fuente: Cálculos propios a partir de la ENCV 1997, 2010 y 2014

${ }^{8}$ Finca, regalo, trueque, supermercado, mercado móvil.

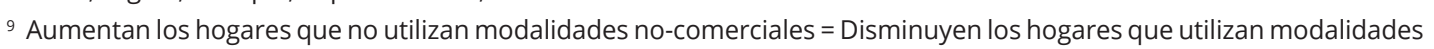
no-comerciales. 
Tabla 2. Continuacion...

\begin{tabular}{cccccc}
1000 & \multicolumn{7}{c}{ Finca } \\
1110 & 0.21 & 1110 & 0.04 & 1110 & 0.05 \\
1100 & 0.37 & 1100 & 0.17 & 1100 & 0.12 \\
110 & 0.21 & 110 & 0.10 & 110 & 0.06 \\
& & 11 & 0.04 & 11 & 0.05 \\
1010 & 5.71 & 1011 & 0.03 & 1011 & 0.02 \\
1000 & 1010 & 1.85 & 1010 & 1.56 \\
100 & 15.45 & 1001 & 0.05 & 1001 & 0.03 \\
10 & 0.33 & 1000 & 10.68 & 1000 & 9.10 \\
& 18.29 & 10 & 0.36 & 100 & 0.19 \\
0 & & 1 & 0.39 & 10 & 8.20 \\
Total & 59.44 & 0 & 76.17 & 0.11 & 80.57 \\
\hline
\end{tabular}

Fuente: Cálculos propios a partir de la ENCV 1997, 2010 y 2014

Mientras que, en sentido contrario, se evidenció un incremento acelerado de los usos de las modalidades comerciales. E, igualmente, se encontró que los hogares combinan una gran cantidad de posibilidades para abastecerse. Las más utilizadas son las tiendas de barrio y los supermercados que no son de cadena (Tabla 3).

Tabla 3. ${ }^{10}$ Modalidades de abastecimiento comercial, 1997-2014 (N expandido - Porcentaje)

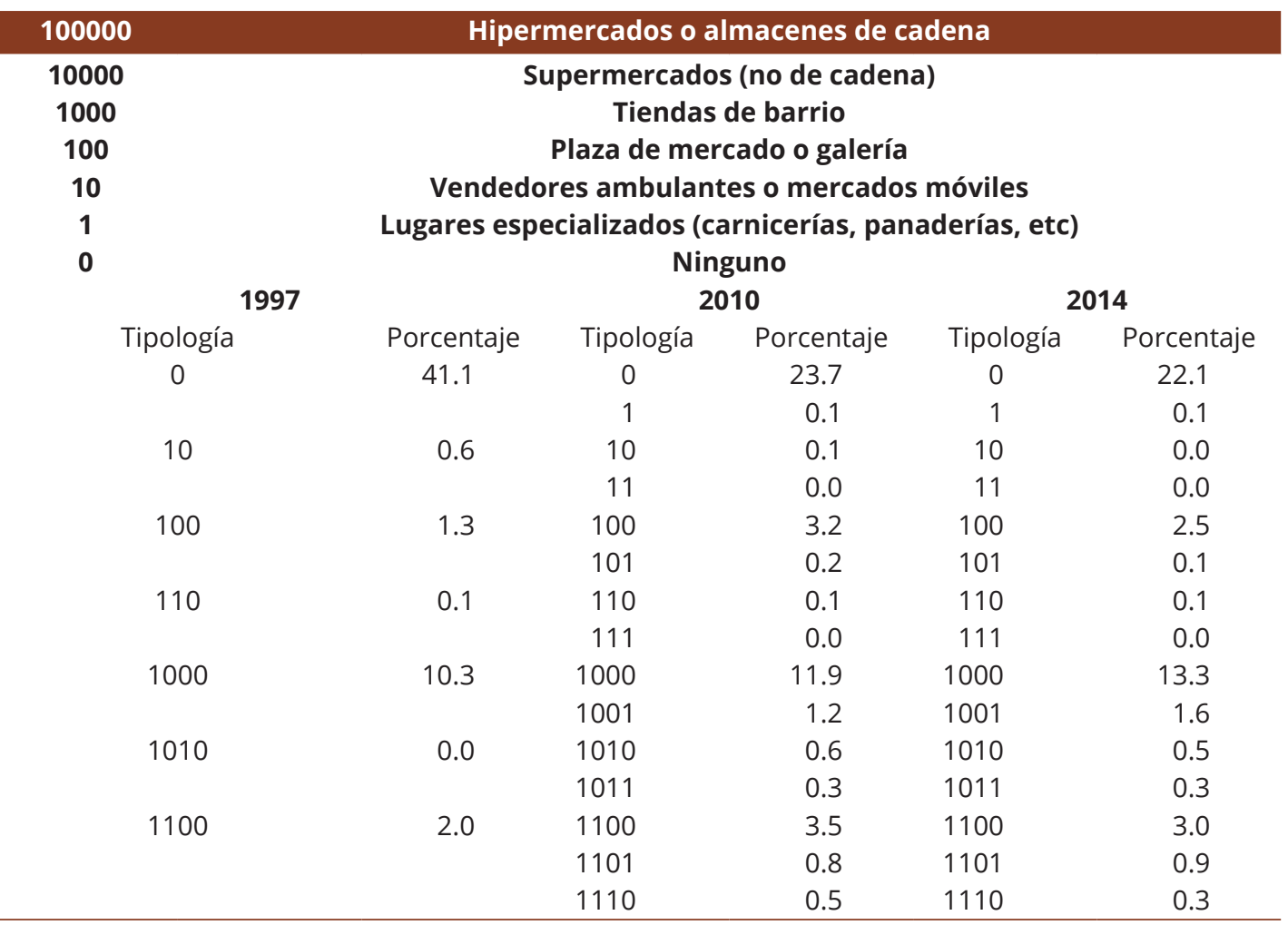

Fuente: Cálculos propios a partir de la ENCV 1997, 2010 y 2014

${ }^{10}$ Disminuyen los hogares que no utilizan modalidades comerciales o en otras palabras: Aumentan los hogares que utilizan modalidades comerciales. 
Tabla 3. Continuacion...

\begin{tabular}{|c|c|c|c|c|c|}
\hline \multirow[t]{2}{*}{100000} & \multicolumn{4}{|c|}{ Hipermercados o almacenes de cadena } & \multirow[b]{2}{*}{0.1} \\
\hline & & 1111 & 0.1 & 1111 & \\
\hline \multirow[t]{2}{*}{10000} & 22.7 & 10000 & 11.6 & 10000 & 17.9 \\
\hline & & 10001 & 2.3 & 10001 & 1.8 \\
\hline \multirow[t]{2}{*}{10010} & 0.2 & 10010 & 0.4 & 10010 & 0.2 \\
\hline & & 10011 & 0.4 & 10011 & 0.1 \\
\hline \multirow[t]{4}{*}{10100} & 1.2 & 10100 & 2.9 & 10100 & 2.9 \\
\hline & & 10101 & 1.8 & 10101 & 1.3 \\
\hline & & 10110 & 0.4 & 10110 & 0.2 \\
\hline & & 10111 & 0.2 & 10111 & 0.2 \\
\hline \multirow[t]{4}{*}{11000} & 8.4 & 11000 & 5.4 & 11000 & 5.4 \\
\hline & & 11001 & 3.3 & 11001 & 1.8 \\
\hline & & 11010 & 0.7 & 11010 & 0.4 \\
\hline & & 11011 & 0.4 & 11011 & 0.1 \\
\hline \multirow[t]{4}{*}{11100} & 0.0 & 11100 & 3.8 & 11100 & 3.5 \\
\hline & & 11101 & 2.2 & 11101 & 1.1 \\
\hline & & 11110 & 0.5 & 11110 & 0.3 \\
\hline & & 11111 & 0.2 & 11111 & 0.1 \\
\hline \multirow[t]{2}{*}{100000} & 7.2 & 100000 & 6.3 & 100000 & 7.7 \\
\hline & & 100001 & 0.5 & 100001 & 0.6 \\
\hline \multirow[t]{2}{*}{100010} & 0.0 & 100010 & 0.1 & 100010 & 0.1 \\
\hline & & 100011 & 0.0 & 100011 & 0.0 \\
\hline \multirow[t]{4}{*}{100100} & 0.5 & 100100 & 1.2 & 100100 & 1.1 \\
\hline & & 100101 & 0.3 & 100101 & 0.2 \\
\hline & & 100110 & 0.1 & 100110 & 0.0 \\
\hline & & 100111 & 0.0 & 100111 & 0.0 \\
\hline \multirow[t]{8}{*}{101000} & 2.8 & 101000 & 1.3 & 101000 & 1.3 \\
\hline & & 101001 & 0.4 & 101001 & 0.4 \\
\hline & & 101010 & 0.2 & 101010 & 0.2 \\
\hline & & 101011 & 0.1 & 101011 & 0.1 \\
\hline & & 101100 & 0.9 & 101100 & 0.8 \\
\hline & & 101101 & 0.2 & 101101 & 0.2 \\
\hline & & 101110 & 0.1 & 101110 & 0.1 \\
\hline & & 101111 & 0.0 & 101111 & 0.0 \\
\hline \multirow[t]{15}{*}{110000} & 1.5 & 110000 & 1.6 & 110000 & 2.2 \\
\hline & & 110001 & 0.6 & 110001 & 0.2 \\
\hline & & 110010 & 0.0 & 110010 & 0.1 \\
\hline & & 110011 & 0.0 & 110011 & 0.0 \\
\hline & & 110100 & 0.7 & 110100 & 0.6 \\
\hline & & 110101 & 0.2 & 110101 & 0.1 \\
\hline & & 110110 & 0.0 & 110110 & 0.0 \\
\hline & & 110111 & 0.0 & 110111 & 0.0 \\
\hline & & 111000 & 1.1 & 111000 & 0.7 \\
\hline & & 111001 & 0.4 & 111001 & 0.2 \\
\hline & & 111010 & 0.1 & 111010 & 0.1 \\
\hline & & 111011 & 0.0 & 111011 & 0.0 \\
\hline & & 111100 & 0.5 & 111100 & 0.6 \\
\hline & & 111101 & 0.1 & 111101 & 0.1 \\
\hline & & 111110 & 0.0 & 111110 & 0.0 \\
\hline Total & 100 & Total & 100 & Total & 100 \\
\hline
\end{tabular}

Fuente: Cálculos propios a partir de la ENCV 1997, 2010 y 2014 
Así que, hasta el momento, es posible decir que los hogares han disminuido los usos de modalidades no comerciales; han incrementado los usos de las modalidades comerciales y, además, estos combinan las modalidades y/o las formas o los lugares de abastecimiento contenidas en dichas modalidades. Pero, además, se encontró que los hogares utilizan más de 70 combinaciones posibles para el abastecimiento de alimentos (Tablas 2 y 3 ).

\section{Modelo multinomial ${ }^{11}$}

El modelo estimado tiene como variable dependiente las diferentes modalidades que usan los hogares para abastecerse (Comercial, No comercial o Ambas modalidades). Y las variables independientes son las características socioeconómicas de los hogares. La categoría de referencia es la modalidad comercial:

$\log \frac{\operatorname{Pr}(y=j)}{\operatorname{Pr}(y=1)}=\beta_{0}+\beta_{1}$ Muj $_{i}+\beta_{2}$ Edad $_{i}+\beta_{3}$ Edu $_{i}+\beta_{4}$ MatPiso $_{i}+\beta_{5}$ PPers $_{i}+\beta_{6} \operatorname{Sec}_{i}+\beta_{7} \operatorname{Region}_{i}+\beta_{8} \operatorname{Año}_{i}+\varepsilon$

La variable épsilon de la ecuación responde al componente error de la estimación del modelo. Y parte de la noción de tener presente que las variables observadas pueden alejarse de la curva que modela la ecuación, porque hay componentes que no son capturados por la estimación. Por lo tanto, es necesario revisar el coeficiente Pseudo-R cuadrado para saber qué tanto las variables independientes pueden explicar la variable dependiente. El coeficiente puede tomar valores entre 0 y 1 , y entre más próximo esté a 0 indicaría una asociación baja de las variables independientes con la variable dependiente, y si está más próximo a 1 mostraría que las variables independientes explican en mayor medida la variable dependiente.

Las variables socioeconómicas de los hogares que fueron escogidas para el análisis arrojaron los siguientes resultados (Tabla 4): los hogares conformado sin presencia de mujeres en él, respecto a hogares con presencia de al menos una mujer en el hogar, tienen menores chances $(-0,21)$ de utilizar ambas modalidades $(p<0.01)$ y menores chances $(-0.32)$ de utilizar modalidades no comerciales $(p<0.01)$ que modalidades comerciales ${ }^{12}$.

Los grupos más jóvenes (13-29, 30-59), respecto a la categoría de referencia (60 o más), tienen menores chances $(-0.23$ y -0.24 respectivamente) de utilizar ambas modalidades $(p<0.01)$ que modalidades comerciales, $y$ tienen menores chances $(-0,45$ y $-0,42$ respectivamente) de utilizar modalidades no comerciales que modalidades comerciales $(p<0.01)$.

Los resultados de la variable continua Cantidad de personas en el hogar permite afirmar que existe una asociación negativa con relación al uso de ambas modalidades y con las modalidades no comerciales. Esto sería: a mayor cantidad de personas en el hogar menores serían las chances (-0.01) de uso de ambas modalidades respecto a las modalidades comerciales $(p<0.01)$, y menores serían las chances $(-0.07)$ del uso de las modalidades no comerciales en relación con las modalidades comerciales $(p<0.01)$.

Los hogares con menor nivel educativo, respecto a la categoría de referencia nivel educativo superior, tienen más chances $(0,48)$ de combinar ambas modalidades (comerciales y no comerciales) $(p<0.01)$ que modalidades comerciales y tienen más chances $(1,56)$ de utilizar modalidades no comerciales que modalidades comerciales $(p<0.01)$.

${ }^{11}$ Dado que para el año 1993 la pregunta es ¿Consume de su propiedad? Y las respuestas posibles son Sí o No, para la estimación del modelo no se tuvo presente este año porque no tiene en cuenta las otras modalidades posibles de abastecimiento: regalo o trueque. Por lo que se escogió para la estimación los años 1997, 2010 y 2014, que son años comparables en preguntas y respuestas de las encuestas.

${ }^{12}$ Recordad que la categoría de referencia de la variable dependiente es la modalidad comercial. 
Los hogares con material del piso de la vivienda Tierra, Cemento o Madera, respecto a la categoría de referencia Mármol, cerámica o madera pulida, tienen más chances $(1.15,0.55$ y 1.34 respectivamente) de utilizar ambas modalidades $(p<0.01)$ que modalidades comerciales, y tienen más chances $(1.29,0.39$ y 0.50 respectivamente) de utilizar la modalidad no comercial $(p<0.01)$ que modalidades comerciales.

En el sector rural, respecto a la categoría de referencia sector urbano, se encontró que hay más chances (6) en el sector rural de emplear ambas modalidades $(p<0.01)$ que modalidades comerciales y más chances (1735.51) de utilizar modalidades no comerciales que modalidades comerciales $(p<0.01)$.

A pesar de que la variable Región es una variable de control, se puede reportar que, en todas las regiones, respecto a la categoría de referencia Bogotá-Capital, hay más chances de combinar ambas modalidades $(p<0.01)$ y hay más chances de utilizar modalidades no comerciales $(p<0.01)$ que modalidades comerciales.

Finalmente, sobre el modelo (Tabla 4) vale resaltar que sus pseudo- $\mathrm{R}^{2}$ están por encima del $50 \%$, de tal manera que se considera que las variables independientes escogidas para estimar el modelo y estudiar la variable dependiente, que provienen de la revisión de la literatura, y considerar el contexto colombiano, responden sociológicamente a lo esperado, tanto en términos teóricos como empíricos.

Y al analizar estas variables en el tiempo (Revisar Anexo 1), se puede decir que la diferenciación por las características socioeconómicas de los hogares se mantiene ${ }^{13}$. Este resultado se refiere a la hipótesis 2. Y especialmente el caso para la presencia de las mujeres ${ }^{14}$ en el hogar la situación se acentúa para las modalidades no comerciales en los años 2010 y 2014.

Tabla 4. Modelo multinomial

\begin{tabular}{|c|c|c|c|c|c|c|c|c|c|}
\hline \multirow{2}{*}{$\begin{array}{c}\text { Variable } \\
\text { dependiente }\end{array}$} & \multirow{2}{*}{$\begin{array}{l}\text { Número } \\
\text { de } \\
\text { categoría }\end{array}$} & \multicolumn{3}{|c|}{1997} & \multicolumn{3}{|c|}{2010} & \multicolumn{2}{|c|}{2014} \\
\hline & & Frecuencia & \multicolumn{2}{|c|}{ Porcentaje } & \multicolumn{2}{|c|}{ Frecuencia } & Porcentaje & Frecuencia & Porcentaje \\
\hline $\begin{array}{l}\text { Comercial y No } \\
\text { comercial (Las dos } \\
\text { categorías) }\end{array}$ & (1) & 2828 & \multicolumn{2}{|c|}{40.2} & \multicolumn{2}{|c|}{1474} & 12.3 & 1762 & 11.1 \\
\hline No Comercial & (2) & 1560 & \multicolumn{2}{|c|}{22.2} & \multicolumn{2}{|c|}{3249} & 27.2 & 4125 & 26.0 \\
\hline Comercial & (3) & 2645 & \multicolumn{2}{|c|}{37.6} & \multicolumn{2}{|c|}{7220} & 60.5 & 9969 & 62.9 \\
\hline Total & & 7033 & \multicolumn{2}{|c|}{100} & \multicolumn{2}{|c|}{11943} & 100 & 15856 & 100 \\
\hline \multirow{3}{*}{$\begin{array}{c}\text { Variables } \\
\text { independientes }\end{array}$} & \multicolumn{9}{|c|}{ Modosa } \\
\hline & \multicolumn{2}{|c|}{$\begin{array}{c}\text { Categoría (3)= Ambas } \\
\text { modalidades }\end{array}$} & \multicolumn{3}{|c|}{$\begin{array}{l}\text { Intervalo de confianza } \\
\text { para Exp(B) al 95\% - } \\
\text { Categoría (1) }\end{array}$} & \multicolumn{2}{|c|}{$\begin{array}{c}\text { Categoría }(2)=\text { No } \\
\text { comercial }\end{array}$} & \multicolumn{2}{|c|}{$\begin{array}{c}\text { Intervalo de confianza } \\
\text { para Exp(B) al 95\% - } \\
\text { Categoría (2) }\end{array}$} \\
\hline & $\operatorname{Exp}(B)$ & Sig. & $\begin{array}{l}\text { Límite } \\
\text { inferior }\end{array}$ & & $\begin{array}{l}\text { nite } \\
\text { erior }\end{array}$ & Exp & Sig. & $\begin{array}{l}\text { Límite } \\
\text { inferior }\end{array}$ & $\begin{array}{l}\text { Límite } \\
\text { superior }\end{array}$ \\
\hline $\begin{array}{l}\text { Mujer }=\text { No } \\
\text { Mujer }=\text { Sí }\end{array}$ & 0.79 & $* * *$ & 0.70 & & & 0. & $\star \star \star$ & 0.56 & 0.83 \\
\hline
\end{tabular}

${ }^{a}$ Categoría de referencia (1): Modalidad Comercial. *** $p<0.01, * \star p<0.05, * p<0.1$. Fuente: Cálculos propios a partir de la ENCV 1997, 2010 y 2014

${ }^{13}$ No hay cambios estadísticamente significativos para todas las variables de análisis. En la modalidad "Ambas" (comercial y no comercial) se encuentran cambios principalmente para la variable región y para los materiales del piso del hogar en Tierra y Cemento. Y en la modalidad no-comercial para la variable mujer, la edad (2010), material del piso Cemento (1997) y cantidad de personas (1997 y 2010).

${ }^{14}$ Los resultados de los betas para las variables y las interacciones estimadas $\beta_{1}$ Mujer $=2,894 ; \beta_{15}$ Mujer $* 1997=-3,14 ; \beta_{16}$ Mujer $* 2010=-2,158 \Rightarrow\left(+2,894-3,14-2,158=-2,404 \Rightarrow e^{-2,404}=0.090\right) \Rightarrow(0.090-1) * 100=>-90,9644 \%$. Este resultado se refiere a la hipótesis dos. 
Tabla 4. Continuacion...

\begin{tabular}{|c|c|c|c|c|c|c|c|c|}
\hline \multirow{3}{*}{$\begin{array}{c}\text { Variables } \\
\text { independientes }\end{array}$} & \multicolumn{8}{|c|}{ Modos $^{\mathrm{a}}$} \\
\hline & \multicolumn{2}{|c|}{$\begin{array}{c}\text { Categoría }(3)=\text { Ambas } \\
\text { modalidades }\end{array}$} & \multicolumn{2}{|c|}{$\begin{array}{l}\text { Intervalo de confianza } \\
\text { para Exp(B) al 95\% - } \\
\text { Categoría (1) }\end{array}$} & \multicolumn{2}{|c|}{$\begin{array}{l}\text { Categoría (2)= No } \\
\text { comercial }\end{array}$} & \multicolumn{2}{|c|}{$\begin{array}{l}\text { Intervalo de confianza } \\
\text { para Exp(B) al 95\% - } \\
\text { Categoría (2) }\end{array}$} \\
\hline & $\operatorname{Exp}(B)$ & Sig. & $\begin{array}{l}\text { Límite } \\
\text { inferior }\end{array}$ & $\begin{array}{l}\text { Límite } \\
\text { superior }\end{array}$ & $\operatorname{Exp}(B)$ & Sig. & $\begin{array}{l}\text { Límite } \\
\text { inferior }\end{array}$ & $\begin{array}{l}\text { Límite } \\
\text { superior }\end{array}$ \\
\hline Edad=13-29 & 0.77 & $\star \star \star$ & 0.68 & 0.87 & 0.55 & $* \star \star$ & 0.44 & 0.68 \\
\hline $\begin{array}{l}\text { Edad=30-59 } \\
\text { Edad }=60 \text { o más }\end{array}$ & 0.76 & $\star \star \star$ & 0.70 & 0.82 & 0.58 & $* * *$ & 0.50 & 0.67 \\
\hline $\begin{array}{l}\text { Cantidad de } \\
\text { personas en el } \\
\text { hogar }\end{array}$ & 0.99 & & 0.97 & 1.02 & 0.93 & $\star * *$ & 0.89 & 0.97 \\
\hline $\begin{array}{l}\text { Educación=Menor } \\
\text { Educación=Superior } \\
\text { o más }\end{array}$ & 1.48 & $\star \star \star$ & 1.35 & 1.62 & 2.56 & $* * *$ & 2.06 & 3.18 \\
\hline $\begin{array}{l}\text { Material del } \\
\text { piso=Tierra }\end{array}$ & 2.15 & $\star \star \star$ & 1.74 & 2.66 & 2.29 & $* * *$ & 1.72 & 3.05 \\
\hline $\begin{array}{l}\text { Material del } \\
\text { piso=Cemento }\end{array}$ & 1.55 & $\star \star \star$ & 1.43 & 1.68 & 1.39 & $* * *$ & 1.20 & 1.61 \\
\hline $\begin{array}{l}\text { Material del } \\
\text { piso=Madera }\end{array}$ & 2.34 & $\star \star *$ & 1.96 & 2.80 & 1.50 & $* * *$ & 1.15 & 1.94 \\
\hline \multicolumn{9}{|l|}{$\begin{array}{l}\text { Material del } \\
\text { piso=Mármol, } \\
\text { cerámica, madera } \\
\text { pulida }\end{array}$} \\
\hline Región=Central & 2.94 & $\star \star \star$ & 2.49 & 3.47 & 2.23 & $* * *$ & 1.41 & 3.53 \\
\hline Región=Pacífico & 2.51 & $\star \star *$ & 2.12 & 2.97 & 2.01 & $* * *$ & 1.27 & 3.19 \\
\hline Región=Caribe & 2.04 & $\star \star \star$ & 1.70 & 2.44 & 3.96 & $* * *$ & 2.49 & 6.30 \\
\hline Región=Orinoquía & 2.51 & $\star \star *$ & 2.07 & 3.04 & 2.48 & $* * *$ & 1.53 & 4.02 \\
\hline $\begin{array}{l}\text { Región=Amazonía } \\
\text { Región=Bogotá }\end{array}$ & 3.05 & $\star * *$ & 2.45 & 3.79 & 2.99 & $* * *$ & 1.68 & 5.35 \\
\hline $\begin{array}{l}\text { Sector=Rural } \\
\text { Sector=Urbano }\end{array}$ & 7.00 & $\star \star *$ & 5.98 & 8.20 & 1735.51 & $\star * *$ & 1431.76 & 2103.71 \\
\hline Año=1997 & 3.70 & $\star \star \star$ & 3.29 & 4.15 & 0.10 & $* * *$ & 0.09 & 0.13 \\
\hline Año=2010 & 1.21 & $\star * \star$ & 1.12 & 1.31 & 1.29 & $* * *$ & 1.10 & 1.50 \\
\hline \multicolumn{9}{|l|}{ Año=2014 } \\
\hline Cox y Snell & 0.617 & & & & & & & \\
\hline Nagelkerke & 0.728 & & & & & & & \\
\hline McFadden & 0.511 & & & & & & & \\
\hline
\end{tabular}

aCategoría de referencia (1): Modalidad Comercial. ${ }^{* * *} p<0.01,{ }^{* *} p<0.05, * p<0.1$. Fuente: Cálculos propios a partir de la ENCV 1997, 2010 y 2014

\section{Discusión}

Los resultados evidencian que los hogares colombianos están usando menos las modalidades no comerciales, están dejando de combinar modalidades (comerciales y no comerciales) y están usando más modalidades comerciales. Dentro de las modalidades no comerciales, las modalidades no-comerciales más frecuentes son la autoproducción en finca y los regalos. Y, de las modalidades comerciales, las más utilizadas son las tiendas de barrio o los supermercados que no son de cadena. Estos resultados muestran en la práctica alimentaria el impacto del cambio paulatino de una economía principalmente rural y/o agraria a una economía más tecnificada y de servicios; específicamente en lo que concierne al aprovisionamiento; $y$, de manera más 
puntual, el impacto de dichos cambios en los usos de las modalidades de abastecimiento de alimentos de los hogares colombianos.

Por otra parte, de los resultados también es relevante decir que los hogares combinan múltiples modalidades (comerciales y no comerciales); pero, además, dentro de estas modalidades, los hogares utilizan múltiples formas de abastecerse. En suma, se encontraron 75 combinaciones posibles en las que los hogares pueden abastecerse. Esto muestra un alto grado de complejidad en los usos de los lugares o formas de abastecimiento de los hogares colombianos. Esta complejidad puede explicarse a partir de las diferentes habilidades, motivaciones, posibilidades materiales con las que los hogares cuentan para hacer uso de sus diferentes opciones de modalidades de abastecimiento. En otras palabras, se puede suponer que la existencia de las múltiples combinaciones que ejecutan los hogares colombianos para abastecerse de alimentos se debe a sus posibilidades agenciales y estructurales, de diferentes niveles (Gojard \& Véron, 2018; Lhuissier 2006).

Es decir, por una parte, se puede suponer que los usos de determinados lugares para abastecerse y las múltiples combinaciones posibles se dan por productos, calidades, cantidades, necesidades, gustos y/o la información con la que cuentan los hogares para abastecerse. Pero también, por otra parte, se encuentran otras posibilidades (o limitaciones) materiales contextuales de los hogares de diferentes niveles; como los lugares disponibles y a los que tienen acceso (cercanía o lejanía), las ofertas y/o las temporadas (fiestas, verano, invierno), entre otras condiciones materiales y no materiales que hacen posible el uso de los lugares de abastecimiento de alimentos. Y todo lo anterior, de manera analítica, puede ser aplicado a otros contextos de aprovisionamiento alimentario (Guivant et al., 2010).

Por otra parte, con respecto al estudio de la estratificación social a partir de las características socioeconómicas de los hogares, se encontró que, en resumen, hay más chances (odds) de utilizar modalidades no comerciales o hay más chances (odds) de combinar modalidades de abastecimiento (comerciales y no-comerciales) para hogares con:

a. Al menos una mujer

b. Personas de edades más jóvenes

c. Niveles educativos bajos

d. Niveles de ingresos bajos

e. Baja cantidad de personas

f. Pertenencia al sector rural

g. Pertenencia a todas las zonas que no sean la capital del país

En sentido contrario, entonces, hay más chances de que las modalidades comerciales sean usadas por hogares masculinos, urbanos, de mayores ingresos, de mayores niveles educativos, de mayor cantidad de personas y de la capital.

De estos resultados, llama a especial reflexión el hecho de que la mujer esté asociada a mayores chances de utilizar modalidades no comerciales (autoproducción o regalo). Quizá, posiblemente, porque sus condiciones de pobreza son mayores y son el grupo de población que cuenta con menos ingresos propios (Comisión Económica para América Latina y el Caribe, 2017); condición que se acentúa en las zonas rurales (Comisión Económica para América Latina y el Caribe, 2017). Por lo tanto, en el contexto colombiano, a partir de los resultados obtenidos, es 
posible afirmar que las mujeres están en condiciones de vulnerabilidad alimentaria ${ }^{15}$; y más aún en las zonas rurales si dependen del regalo o si dependen de las condiciones de autoproducción, cuando en la mayoría de los casos no son poseedoras de tierras, ni de maquinarias productivas y además deben vivir las condiciones del conflicto interno armado (Lancheros \& Arias, 2017) ${ }^{16}$.

Pero en términos generales, principalmente en las zonas rurales, donde claramente hay mayores chances de utilizar modalides no-comerciales para el sustento alimenticio, y cuya categoría está conformada principalmente por la autoproducción, la pregunta que surge es: ¿en qué condiciones lo están haciendo? Si se tiene en cuenta que en las zonas rurales hay altos índices de violencia y permanencia del conflicto interno armado ${ }^{17} ; \mathrm{y}$-además- por una parte, sostener un cultivo requiere de un gran esfuerzo por parte de los hogares (en dinero, maquinaria, abonos); y, por otra parte, el tiempo y los procesos naturales propios de una siembra, un regado o una cosecha no proporcionan un resultado inmediato con el que suplir una necesidad vital, como es el consumo de alimentos.

Adicionalmente, para el caso colombiano, de las modalidades no comerciales, el regalo llama especialmente la atención, al ser este una de las formas más empleadas de las modalidades no comerciales, después de la autoproducción. Si bien este trabajo es bajo metodología cuantitativa, no se debe perder de vista que el regalo es una forma de intercambio en la que subyacen simbolismos, vínculos y otras motivaciones relacionadas con la interacción social (Mauss, 1971; Le Velly, 2012). Pero, además, siendo que es en las zonas rurales donde más puede darse este uso, el lector debe saber que es en estas zonas donde hay mayores grupos de comunidades indígenas y afrodescendientes, cuyos intercambios podrían tomar mayores valores simbólicos ${ }^{18}$.

De las modalidades comerciales es relevante resaltar que disminuyó el uso de las ventas ambulantes, se incrementó el uso de las tiendas de barrio, de los supermercados que no son de cadena y de los supermercados de cadena. Así pues, estamos frente a prácticas de aprovisionamiento alimentario que aún entrecruzan lo tradicional y lo moderno, lo rural y lo urbano, las diferencias de género, las desigualdades de ingreso, los contrastes regionales o aspectos políticos. Por lo tanto, como categoría analítica teórica y empírica, los lugares de abastecimiento de alimentos y sus modalidades ayudan a revelar las tensiones agencia/ estructura del aprovisionamiento por parte de los hogares; y de las transformaciones del sistema productivo en la práctica de abastecimiento de alimentos por parte de los hogares colombianos.

De modo que el trabajo metodológico desarrollado en este artículo permite asegurar —en términos empíricos- que no sólo hablamos del despliegue de un gran conjunto de recursos materiales y no materiales de los hogares para utilizar las posibilidades de abastecimiento con las que cuentan; sino que también se puede asumir que las condiciones socioeconómica, así como los hogares y el contexto en el que estos habitan, impactan en las diferentes formas de abastecerse.

${ }^{15}$ Y la vulnerabilidad alimentaria podría inferirse para otros grupos sociales, como aquellos con bajos niveles educativos, bajos niveles de ingresos, jóvenes o campesinos que no utilicen modalidades comerciales.

${ }^{16}$ Los resultados Ilaman a especial atención a la seguridad alimentaria en el país.

${ }^{17} \mathrm{Si}$ bien un sector de la población colombiana desconoce la categoría de 'conflicto interno armado' para describir la situación política colombiana.

${ }^{18}$ En esta línea, vale reconocer que una aproximación cuantitativa a esta problemática hace perder de vista los detalles de la interacción social subyacente en dichos intercambios. 


\section{Conclusiones}

Este artículo tenía como objetivo mostrar la relación de las condiciones socioeconómicas de los hogares colombianos en la práctica alimentaria del aprovisionamiento, específicamente en lo que corresponde a los usos de las modalidades de abastecimiento (comercial, no comercial y el uso de ambas modalidades). El punto de partida fueron dos hipótesis:

1. El uso de las modalidades comerciales se incrementó en el periodo 1993-2014.

2. El uso de las modalidades comerciales se incrementa en las zonas urbanas, en hogares con hombres, con altos niveles educativos y con altos niveles de condiciones de vida.

Dichas hipótesis han guiado este texto a cinco resultados principales:

1. Colombia es un país en vías de desarrollo, principalmente rural y agrario, con altos niveles de violencia, pobreza y desigualdad; que está atravesando un proceso de transformación institucional gubernamental, con miras a transformar su estructura productiva. Estas transformaciones han tenido impacto en diferentes esferas cotidianas de los hogares colombianos. La práctica alimentaria es un elemento de la vida cotidiana que se está trasformando. De la práctica alimentaria, se puede afirmar que hay cambios paulatinos en la etapa y/o proceso de aprovisionamiento.

2. Bajo estadística descriptiva se puede afirmar lo siguiente. Primero, que el uso de las modalidades no comerciales disminuye, mientras que el uso de modalidades comerciales se incrementa. Segundo, si se tiene en cuenta que las chances de usar ambas modalidades respecto a la comercial son de 2,70 en 1997, y de 0,21 en 2010; entonces se puede decir que el hecho de que la población esté transitando hacia las modalidades comerciales, hace que las chances de usar ambas modalidades, respecto a la categoría de referencia comercial, estén disminuyendo en el tiempo. Y tercero, para el año 1997 hay menos chances de utilizar modalidades no comerciales que modalidades comerciales, respecto al año 2014. Estos resultados permiten afirmar que hay un incremento en los usos de las modalidades comerciales, pero esto no niega que aún perdura el uso de las modalidades no comerciales. Lo que se está planteando es un cambio paulatino en los usos de las modalidades comerciales y no comerciales.

3. Entre las modalidades comerciales y no comerciales, se evidenció que los hogares colombianos utilizan y combinan una variada gama de posibilidades de lugares y formas para abastecerse de alimentos (autoproducción, regalos, supermercados, tiendas, lugares especializados). Los resultados evidencian que hay al menos 75 combinaciones posibles de aprovisionamiento. Esto demuestra un gran trabajo y esfuerzo por parte de los hogares para decidir de dónde van a obtener sus alimentos. Esto indica que hay un amplio conjunto de dispositivos (materiales o no-materiales) de los hogares y del contexto descrito que posibilitan o limitan el acceso a los alimentos.

4. Hay asociaciones estadísticamente significativas de las condiciones socioeconómodmicas de los hogares en las chances (odds) de utilizar las diferentes modalidades de análisis (comercial, no-comercial, ambas). Esto significa que existe una diferenciación o estratificación socioeconómica en lo que corresponde al uso de las modalidades de abastecimiento.

5. Estadísticamente se puede inferir vulnerabilidad alimentaria para la mujer, en especial para la mujer rural, y para otros grupos de la sociedad colombiana. 
Ahora bien, dentro de las limitaciones del estudio, se quiere señalar la escasez de datos cuantitativos para continuar comprendiendo la complejidad actual del acceso a los alimentos en Colombia, si se tiene en cuenta que el país se viene transformando aceleradamente. $Y$ también se llama a reflexionar, como futura línea de investigación y profundización, sobre las condiciones de vulnerabilidad y/o seguridad alimentaria de diferentes grupos de la población colombiana y el empleo de metodología cualitativa.

\section{Agradecimientos}

Quiero mostrar mis agradecimientos al Centre Maurice Halbwachs (Centre National de la Recherche Scientifique, École Normale Supérieure, École des Hautes Études en Sciences Sociales), donde tuve la oportunidad de realizar mis estancias de investigación, especialmente a las investigadoras Séverine Gojard, Marie Plessz y Anne Lhuissier por los textos y los diálogos compartidos. También expreso mi gratitud a Luis Maldonado, del Instituto de Sociología de la Pontificia Universidad Católica de Chile y a los evaluadores dobles ciegos por las sugerencias constructivas que contribuyeron a mejorar la versión final de este artículo, y a la Universidad Santiago de Cali por motivar e incentivar la investigación.

\section{Financiación}

La realización de este trabajao fue posible gracias a la Comisión Nacional de Investigación Científica y Tecnológica de Chile, CONICYT-PCHA/Beca Doctorado Nacional/2017-21170258. La edición y publicación fue gracias a la Universidad Santiago de Cali.

\section{Referencias}

Bonnain-Moerdijk, R. (1975). L'alimentation paysanne en France entre 1850 et 1936. Etudes Rurales, 58, 29-49. http://dx.doi.org/10.3406/rural.1975.2019.

Bourdieu, P. (1998). La distinción. Madrid: Grupo Santillana de Ediciones.

Bove, C. F., \& Sobal,J. (2006). Foodwork in newly married couples. Food, Culture, \& Society, 9(1), 69-89.

Comisión Económica para América Latina y el Caribe - CEPAL. (2017). Anuario estadístico de América Latina y el Caribe. Santiago: Naciones Unidas.

Dubuisson-Quellier, S. (1999). Le prestataire, le client et le consommateur: sociologie d'une relation marchande. Revue Française de Sociologie, 4Q(4), 671-688. http://dx.doi.org/10.2307/3322854.

Dufy, C., \& Weber, F. (2007). L'ethnographie économique. Paris: La Découverte.

Eymard, I. (1999) De la grande surface au marché: à chacun ses habitudes(INSEE Premier, No. 636).

Gojard, S., \& Véron, B. (2018). Shopping and cooking: the organization of food practices, at the crossing of access to food stores and households properties in France. Review of Agricultural, Food and Environmental Studies, 99(1), 97-119. http://dx.doi.org/10.1007/s41130-018-0068-7

Gojard, S., Plessz, M., \& Régnier, F. (2017). Les femmes et l'alimentation: le rôle des normes alimentaires et corporelles. Institut National de la Recherche Agronomique: Sciences Sociales, 1-2, 1-7.

Grignon, C., \& Grignon, C. (1980). Styles d'alimentation et goûts populaires. Revue Française de Sociologie, 21(4), 531-569.

Guivant, J., Spaargaren, G., \& Rial, C. (2010). Novas práticas alimentares no mercado global. Florianópolis: Editora da UFSC. 
Halbwachs, M. (1933). L'évolution des besoins dans les classes ouvrières. Paris: Librairie Félix Alcan.

Heeringa, S., West, B., \& Berglund, P. (2010). Applied survey data analysis (Statistic in the Social and Behavioral Sciences Series). Boca Raton: Chapman \& Hall/CRC, Taylor \& Francis Group.

Holm, L., \& Kjærnes, U. (2006). Social factors and food choice: consumption as practice. In L. Frewer \& H. van Trijp (Eds.), Understanding consumers of food products (pp. 511-533). Cambridge: Woodhead Publishing.

Lancheros, C., \& Arias, L. (2017). Mujeres rurales en Colombia. Informes País.

Larmet, G. (2002). L'organisation des achats alimentaires. Cahiers d'Économie et de Sociologie Rurales, 63, 51-84.

Le Velly, R. (2012). Sociologie du marché. Paris: La Découverte.

Lhuissier, A. (2006). Pauvreté, monoparentalité et al.mentation. Cahiers de Nutrition et de Diététique, 41(2), 104-110. http://dx.doi.org/10.1016/S0007-9960(06)70614-9

Lhuissier, A. (2018) Alimentation populaire. In J. P. Poulain (Ed.), Dictionnaire des cultures alimentaires (pp. 45-49). Paris: Presses Universitaires de France.

Mauss, M. (1971). Ensayo sobre los dones: motivo y forma del cambio en las sociedades primitivas. In M. Mauss (Ed.), Sociología y antropología (pp. 155-258). Madrid: Editorial Tecnos.

Perry, G. (2011). Economía y constitución. In Constitución de 1991, 20 años: logros y pendientes (pp. 38-39). Bogotá: Universidad de los Andes.

Plessz, M., Dubuisson-Quellier, S., Gojard, S., \& Barrey, S. (2014). How consumption prescriptions affect food practice: assessing the roles of households resources and life course. Journal of Consumer Culture, 16(1), 101-123.

Poulain, J.-P. (2002). Sociologies de l'alimentation: les mangeurs et l'espace social alimentaire. Paris: Presses Universitaires de France.

Reckwitz, A. (2002). Toward a theory of social practices: a development in culturalist theorizing. European Journal of Social Theory, 5(2), 243-263.

Régnier, F., Lhuissier, A., \& Gojard, S. (2006). Sociologie de l'alimentation. Paris: La Découverte.

Schatzki, T., Knorr, K., \& Von Savignay, E. (2001). The practice turn in contemporary theory. London: Routledge.

Steiner, P. (2011). La sociologie économique. Paris: La Découverte.

Warde, A. (1997). Consumption, food and taste: culinary antinomies and commodity culture. London: SAGE Publications.

Warde, A. (2016) The practice of eating. London: Polity Press. 


\section{Anexo 1 - Modelo multinomial de cambio ${ }^{19}$}

\begin{tabular}{|c|c|c|c|c|}
\hline \multirow{3}{*}{ Variables independientes } & \multicolumn{4}{|c|}{ Modos $^{a}$} \\
\hline & \multicolumn{2}{|c|}{ Categoría (1)= Ambas modalidades } & \multicolumn{2}{|c|}{ Categoría $(2)=$ No comercial } \\
\hline & $\operatorname{Exp}(B)$ & Sig. & $\operatorname{Exp}(B)$ & Sig. \\
\hline Mujer=No &, 696 & 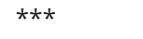 & 18,066 & $* * *$ \\
\hline \multicolumn{5}{|l|}{ Mujer=Sí } \\
\hline Edad & 1,008 & $* \star *$ & & \\
\hline Educación=Menor & 1,457 & $* * *$ & & \\
\hline \multicolumn{5}{|l|}{ Educación=Superior o más } \\
\hline Material del piso=Tierra & 2,615 & $* \star *$ & & \\
\hline Material del piso $=$ Cemento & 1,685 & $* * *$ & & \\
\hline Material del piso=Madera & 2,095 & $* * *$ & & \\
\hline \multicolumn{5}{|l|}{$\begin{array}{l}\text { Material del piso=Mármol, cerámica, } \\
\text { madera pulida }\end{array}$} \\
\hline Cantidad de personas en el hogar & 980 & & & \\
\hline Sector=Rural & ,633 & $\star \star \star *$ & & \\
\hline \multicolumn{5}{|l|}{ Sector=Urbano } \\
\hline Región=Central & 3,814 & $\star \star \star *$ & & \\
\hline Región=Pacífico & 3,883 & 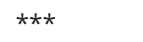 & & \\
\hline Región=Caribe & 2,817 & $* \star \star$ & & \\
\hline Región=Orinoquía & 2,234 & $\star \star \star *$ & & \\
\hline Región=Amazonía & 5,250 & 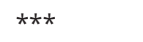 & & \\
\hline \multicolumn{5}{|l|}{ Región=Bogotá } \\
\hline Año=1997 & 4,695 & $* \star *$ & & \\
\hline Año=2010 & 1,776 & $* *$ & & \\
\hline \multicolumn{5}{|l|}{ Año=2014 } \\
\hline Año $=1997 *$ Mujer $=$ No & 1,235 & & ,043 & $* * *$ \\
\hline Año $=2010 *$ Mujer $=$ No & 1,097 & &, 116 & $* * *$ \\
\hline Año $=1997 *$ Edad & 1,002 & & 1,025 & \\
\hline Año $=2010 *$ Edad & 1,000 & & 1,030 & * \\
\hline \multicolumn{5}{|l|}{ Año $=1997 *$ Educa $=$ Menor } \\
\hline \multicolumn{5}{|l|}{ Año $=2010 *$ Educa $=$ Menor } \\
\hline \multicolumn{5}{|l|}{ Año=1997 * Material del piso=Tierra } \\
\hline Año=1997 * Material del piso=Cemento & 1,044 & & 3,124 & * \\
\hline \multicolumn{5}{|l|}{ Año=1997 * Material del piso=Madera } \\
\hline Año=2010 * Material del piso=Tierra & 665 & * & & \\
\hline Año $=2010 *$ Material del piso $=$ Cemento & ,781 & $* * *$ & & \\
\hline \multicolumn{5}{|l|}{ Año=2010 * Material del piso=Madera } \\
\hline \multicolumn{5}{|l|}{ hogar } \\
\hline Año $=2010 *$ Cantidad de personas en el & & & 654 & ** \\
\hline \multicolumn{5}{|l|}{ hogar } \\
\hline \multicolumn{5}{|l|}{ Año=1997 *Sector $=$ Rural } \\
\hline \multicolumn{5}{|l|}{ Año=2010 *Sector=Rural } \\
\hline Año=1997 *Región=Central & 600 & $\star *$ & & \\
\hline Año=1997 *Región=Pacífico & 275 & $* * *$ & & \\
\hline Año=1997 *Región=Caribe & ,339 & *** & & \\
\hline \multicolumn{5}{|l|}{ Año=1997 *Región=Orinoquía } \\
\hline Año=1997 *Región=Amazonía & 277 & $* * *$ & & \\
\hline Año=2010 *Región=Central & 653 & $* *$ & & \\
\hline Año $=2010 *$ Región $=$ Pacífico &, 546 & $* \star *$ & & \\
\hline Año=2010 *Región=Caribe & 692 & $\star \star$ & & \\
\hline \multicolumn{5}{|l|}{ Año=2010 *Región=Orinoquía } \\
\hline Año=2010 *Región=Amazonía &, 514 & $* * *$ & & \\
\hline
\end{tabular}

aCategoría de referencia Comercial. Fuente: Cálculos propios a partir de la ENCV 1997, 2010 y 2014

${ }^{19}$ Se presentan solo las variables con resultados estadísticamente significativos. 